OPEN ACCESS

Edited by:

Gabriele Simonini,

University of Florence, Italy

Reviewed by:

Andrea Taddio,

IRCCS Materno Infantile Burlo

Garofolo (IRCCS), Italy

Lovro Lamot,

University Hospital Center

Zagreb, Croatia

Fatma Dedeoglu,

Boston Children's Hospital and

Harvard Medical School,

United States

${ }^{*}$ Correspondence: Angelo Mazza

amazza@asst-pg23.it

Specialty section:

This article was submitted to

Pediatric Immunology,

a section of the journal

Frontiers in Pediatrics

Received: 13 November 2020 Accepted: 07 January 2021

Published: 28 January 2021

Citation:

Mazza A, Di Giorgio A, Martelli L

Pelliccia C, Pinotti MA, Quadri V,

Verdoni L, Decio A, Ruggeri $M$ and

D'Antiga $L$ (2021) Patterns of

Presentation of SARS-CoV-2 Infection

in Children. Experience at the Italian

Epicentre of the Pandemic.

Front. Pediatr. 9:629040.

doi: 10.3389/fped.2021.629040

\section{Patterns of Presentation of SARS-CoV-2 Infection in Children. Experience at the Italian Epicentre of the Pandemic}

\author{
Angelo Mazza ${ }^{1 *}$, Angelo Di Giorgio ${ }^{2}$, Laura Martelli ${ }^{3}$, Ciretta Pelliccia ${ }^{4}$, \\ Moira Alessandra Pinotti ${ }^{4}$, Vera Quadri ${ }^{5}$, Lucio Verdoni ${ }^{6}$, Alice Decio ${ }^{7}$, Maurizio Ruggeri ${ }^{8}$ \\ and Lorenzo D'Antiga ${ }^{8}$ \\ ${ }^{1}$ Paediatric Pulmonology, Paediatric Department, Hospital Papa Giovanni XXIII, Bergamo, Italy, ${ }^{2}$ Paediatric Gastroenterology, \\ Paediatric Department, Hospital Papa Giovanni XXIII, Bergamo, Italy, ${ }^{3}$ Paediatric Nephrology, Paediatric Department, \\ Hospital Papa Giovanni XXIII, Bergamo, Italy, ${ }^{4}$ Paediatric Endocrinology, Paediatric Department, Hospital Papa Giovanni \\ XXIII, Bergamo, Italy, ${ }^{5}$ Paediatric Allergology, Paediatric Department, Hospital Papa Giovanni XXIII, Bergamo, Italy, \\ ${ }^{6}$ Paediatric Rheumatology, Paediatric Department, Hospital Papa Giovanni XXIII, Bergamo, Italy, ${ }^{7}$ Child Neuropsychiatry \\ Service, Hospital Papa Giovanni XXIII, Bergamo, Italy, ${ }^{8}$ Paediatric Department, Hospital Papa Giovanni XXIII, Bergamo, Italy
}

Background: COVID-19, a disease caused by the new coronavirus SARS-CoV-2, spread worldwide, and Bergamo was one of the most affected areas in Europe. Following the first outbreak, more than half of the population of the Bergamo province had been infected. We aimed to describe the patients admitted to our unit shortly after the first outbreak.

Methods: we retrospectively reviewed the notes of all pediatric patients diagnosed with COVID-19. We enrolled patients with positive swabs or serology and classified them based on the pattern and the timing of presentation after the first outbreak. This setting was considered a reliable reflection of the consequences of unmitigated SARS-CoV-2 circulation.

Results: We diagnosed 35 patients over a 3-month period and we identified six patterns presenting in two temporal phases: Early phase, Group 1 (median of 20 days from epidemic start, IQR: 15-27): neonatal sepsis (n.7), pneumonia (n.5), flu-like symptoms (n.2). Late phase, Group 2 (59:51-66 days, $p<0.001)$ : MIS-C (n.18), neurological manifestations (n.3). Group 1 differed from Group 2 for younger age (1 vs. 8 years, $p=0.02)$, lower C-reactive protein (0.9 vs. $16.6 \mathrm{mg} / \mathrm{dl}, p=0.008)$, procalcitonin $(0.16$ vs. $7.9 \mathrm{ng} / \mathrm{ml}, p=0.008$ ) and neutrophil count (3,765 vs. $6,780 / \mu \mathrm{l}, p=0.006)$, higher rate of positive swabs (14/14 vs. 9/21, $p<0.001)$, higher lymphocyte count (3,000 vs. $930 / \mu \mathrm{l}, p=0.006)$ and platelet count (323,000 vs. $210,000 / \mu \mathrm{l}, p=0.009$ ).

Conclusions: Following an outbreak of unmitigated SARS-CoV-2 diffusion, infected children may present with clinical patterns suggesting two temporal clusters, the first characterized by markers of direct viral injury, the second suggesting an immune-mediated disease.

Keywords: COVID-19, children, clinical manifestation, SARS-CoV-2, immunity 


\section{INTRODUCTION}

The SARS-CoV-2 epidemic, causing a disease named "COVID19," has spread worldwide since the beginning of 2020. Italy was the first European country to be involved and Bergamo, the most affected city in the first wave of the epidemic. In Italy 960,373 infected people and 41,750 deaths have been reported as of November 9. Overall 265,531 cases occurred in Lombardy, of which 20,390 in Bergamo (1). Shortly after the free circulation of the virus, a local study revealed that $56 \%$ of the population of the Bergamo province had been infected by SARS-CoV-2 (2).

These numbers argue why Bergamo and its area (around $1,200,000$ inhabitants in all) have become a model of the impact of COVID-19 epidemic on people's health.

COVID-19 presents different patterns of clinical presentation in adults and children (3). In adults, the clinical picture is dominated by interstitial pneumonia possibly complicated by cardiovascular involvement. Following the infection of an adult person, a three-phase course of the disease has been described, with a progression from initial involvement of the upper airways to abnormal chest imaging due to the descent of the virus to the alveolar cells; the third phase is characterized by a vigorous immune response of the host, leading to a cytokine storm, with elevated inflammatory and cardiac biomarkers associated with severe interstitial pneumonia (4).

In children the clinical presentation is mild, mostly with an influenza-like pattern (5). Serious cases are rare and full recovery is the rule. Few cases require hospitalization, but the majority of children can be managed as outpatients or have an asymptomatic course $(5,6)$.

The aim of this study is to analyze the clinical pattern of pediatric patients admitted to our unit during the first 3 months of the outbreak of SARS-CoV-2 in Bergamo, following a period of unmitigated viral circulation.

\section{PATIENTS AND METHODS \\ Study Setting}

In this study we retrospectively reviewed the notes of patients admitted to the general paediatric unit of Hospital Papa Giovanni XXIII in Bergamo (Italy), and managed as inpatients, from February 25 to May 23, 2020. Our unit is a tertiary pediatric referral center with $\sim 1,300$ pediatric admissions per year, serving a province of approximately one million people.

From the start of the epidemic we set up a dedicated COVID area in our general pediatric ward, hosting all patients/parents with a positive nasopharyngeal/oropharingeal (NP/OP) swab,

\footnotetext{
Abbreviations: SARS-CoV-2, severe acute respiratory syndrome coronavirus 2; COVID-19, coronavirus disease-19; MIS-C, Multisystem inflammatory syndrome in children; NP/OP, nasopharyngeal/oropharingeal; PPE, personal protective equipment; RT-PCR, reverse-transcriptase polymerase-chain-reaction; ICU, intensive care unit; IL-6, interleukin-6; PCR, polymerase chain reaction; WBC, white blood cells; IVIG, intravenous immunoglobulin; ASA, Acetyl salicylate acid; CRP, C-reactive protein; LDH, lactate dehydrogenase; ALT, Alanine aminotransferase; IQR, interquartile range; $\mathrm{ACE}-2$, angiotensin converting enzyme-2; TGF- $\beta$, transforming growth factor- $B$; IL-10, Interleukin-10.
}

managed with full isolation and personal protective equipment (PPE) (7).

No other hospitals in our area created a COVID-19 dedicated area. The patients were admitted in the first phase of the epidemic and during the lockdown, therefore we considered this situation a reliable reflection of the consequences of unmitigated SARS$\mathrm{CoV}-2$ circulation in the pediatric population of the province of Bergamo.

\section{Confirmation of SARS-CoV-2 Infection}

During the study period all patients admitted to our unit underwent NP/OP, testing SARS-CoV-2 nucleic acid using realtime reverse-transcriptase polymerase-chain-reaction (RT-PCR) assay; patients with a positive NP/OP test were considered confirmed cases of SARS-CoV-2 infection.

A proportion of patients admitted to our unit underwent also a test for the qualitative detection of SARS-CoV-2 antibodies (IgM and IgG) through a lateral flow chromatographic immunoassay (NADAL ${ }^{\circledR}$ COVID-19 IgG/IgM Test, nal von minden GmbH, Carl Zeiss Strasse 12, 47445 Moers, Germany). Positivity of IgM and/or IgG was considered consistent with a recent or previous infection by SARS-CoV-2, respectively.

\section{Definitions}

Among all admissions we identified those who were related to SARS-CoV-2 infection based on NP/OP and serology testing (here referred to as "COVID-19"). COVID-19 patients were analyzed to ascertain different patterns of presentation by age and symptoms. We classified COVID-19 patients into six categories, based on previous reports on manifestations of SARS-CoV-2 in children (8).

- Neonatal/Infantile viral sepsis: patients meeting the criteria for paediatric systemic inflammatory response syndrome (SIRS) (at least two from fever, tachycardia, tachypnea, elevated leukocyte count; one of two must be fever or abnormal leukocyte count) in children under 3 months of age (9).

- Pneumonia: presence of a compatible chest X ray.

- Influenza-like syndrome: history of fever and upper respiratory tract symptoms.

- Multisystem inflammatory syndrome in children (MIS-C): Age $<21$ years and a presentation including all of the following:

${ }^{\circ}$ Fever $>38.0^{\circ} \mathrm{C}$ for $\geq 24 \mathrm{~h}$, or report of subjective fever lasting $\geq 24 \mathrm{~h}$;

- Laboratory evidence of inflammation including one or more from: elevated C-reactive protein, erythrocyte sedimentation rate, fibrinogen, procalcitonin, D-dimer, ferritin, lactic acid dehydrogenase, or interleukin-6 [IL6] level, elevated neutrophils, reduced lymphocytes and low albumin;

- Severe illness requiring hospitalization;

$\circ \geq 2$ organ systems involved (cardiac, renal, respiratory, hematologic, gastrointestinal, dermatologic, and/or neurologic);

- No alternative plausible diagnoses;

- Recent or current SARS-CoV-2 infection or exposure, defined as any of the following: Positive SARS-CoV-2 


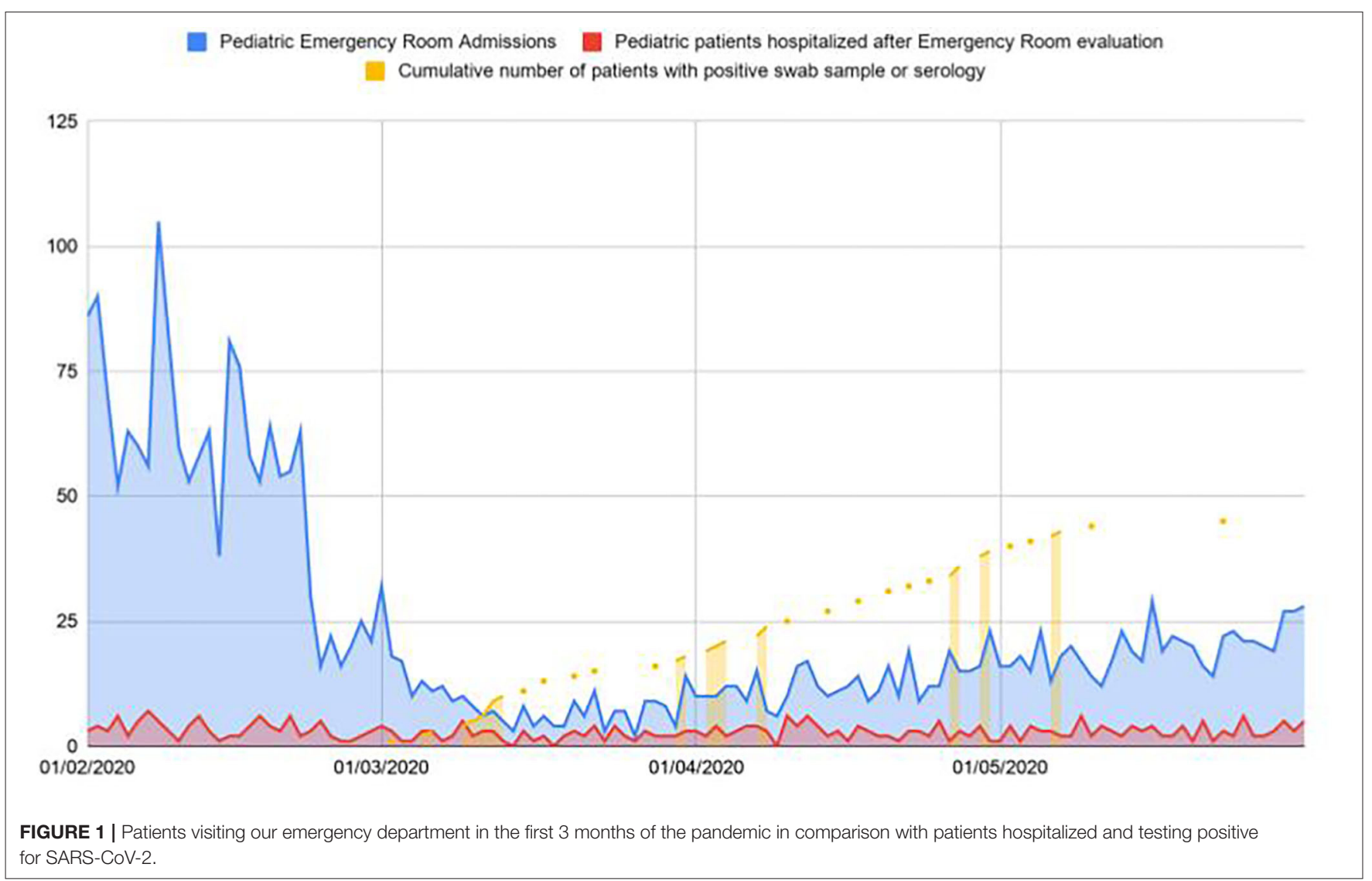

polymerase chain reaction (PCR); Positive serology for SARS-CoV-2; Positive antigen test; COVID-19 exposure within the 4 weeks prior to the onset of symptoms (10).

- Neurological manifestations: any symptoms related to nervous system involvement requiring hospitalization.

- Miscellaneous: NP/OP positive for SARS-CoV-2 but admitted for reasons unrelated to COVID-19 (surgical problems, trauma, chemotherapy or skin rash) and managed in our pediatric COVID area.

\section{Clinical, Laboratory and Radiological Evaluation}

Data obtained from the hospital medical records populated an ad hoc database and included demographic informations, presenting symptoms, contact with confirmed or suspected cases of COVID19, laboratory data (including white blood cell count, neutrophils and lymphocyte count, C-reactive protein (CRP), pro-calcitonin, lactate dehydrogenase (LDH), Alanine aminotransferase (ALT) and creatinine). Chest X-ray was evaluated when performed.

\section{Statistical Analysis}

The Student $t$-test, the $\chi 2$ method, or Fisher's exact test were performed when appropriate to compare continuous and categorical variables. A $P$-value $<0.05$ was chosen as cut-off for significance. Data were analyzed with SPSS (IBM Corp. Released 2011. IBM SPSS Statistics for Mac, Version 20.0.
Armonk, NY: IBM Corp) and GraphPad Prism (GraphPad Prism version 5.00 for Mac, GraphPad Software, San Diego, CA) softwares. The study received the approval of the Bergamo Ethics Committee within the frame of the proposal entitled "Retrospective observation for a better understanding of epidemiology and outcome of COVID-19 disease"(registration n. 37/20, 25/03/2020).

\section{RESULTS}

\section{Study Group}

From February 25 to May 23, 153 patients were admitted to our unit. In the same period of the previous year we admitted 173 patients. All the 153 patients performed a NP/OP for SARS-CoV-2 and 33 resulted positive. Twenty patients of the 153 also performed a serological test with a positive result in 15. Three of these patients had a positive NP/OP sample as well. Figure 1 reports data regarding patients visiting our emergency department, providing information on percentage of hospitalizations and discharge.

Overall, 45/153 (32\% of all admitted) patients were diagnosed with COVID-19 presenting as: viral sepsis ( $n .7)$, pneumonia (n. 5), flu-like symptoms ( $n .2)$, MIS-C ( $n$. 18), neurological manifestations (n.3). The remaining 10 patients were admitted to our pediatric COVID-19 area because of the positive result of the NP/OP swab screening, but without a clinical pattern in keeping 


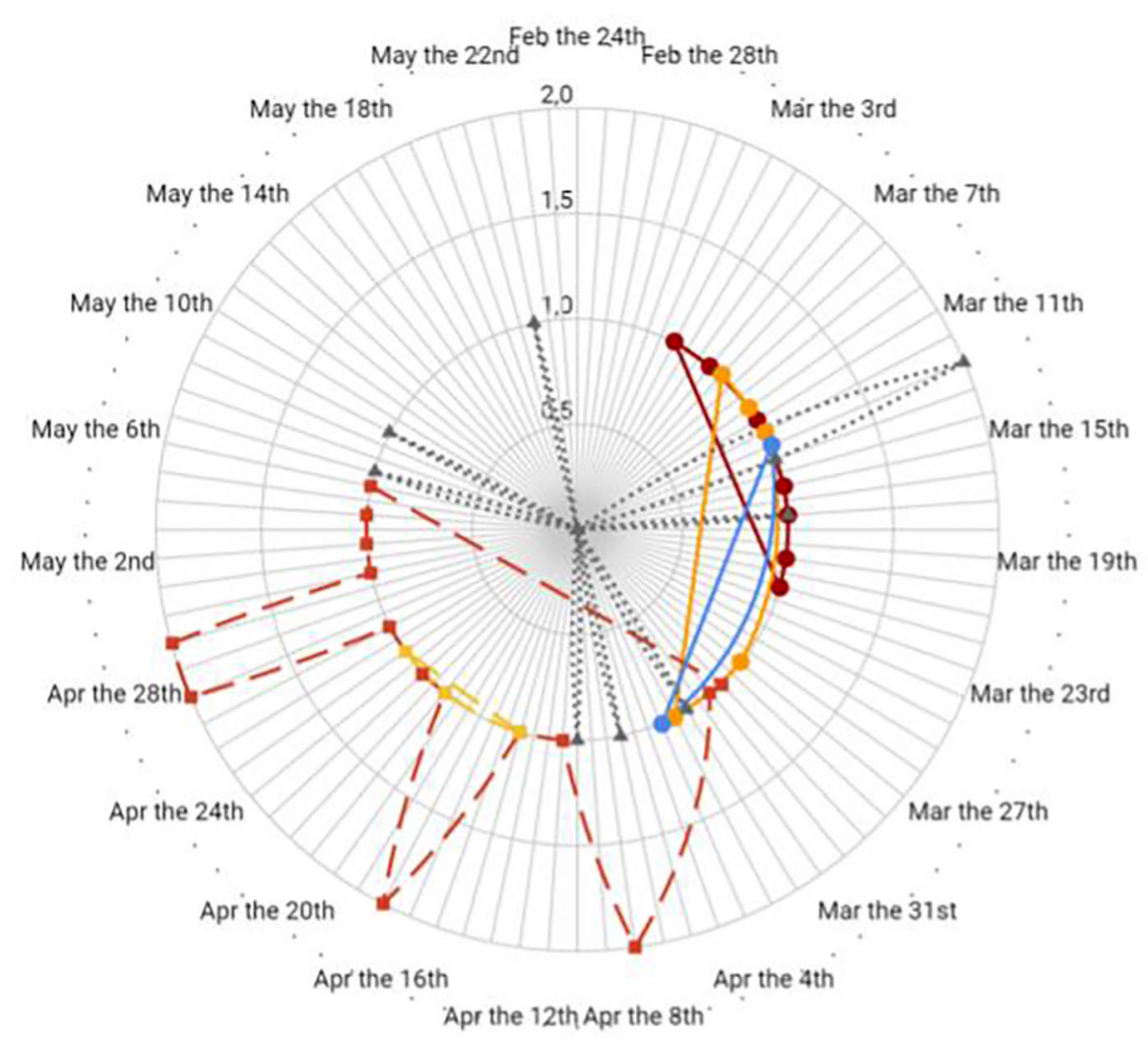

Viral sepsis

Pneumonia

MIS-C

Neurological manifestations

Others

Influenza-like

FIGURE 2 | Timeline distribution of patients divided by clinical pattern of presentation diagnosis. Solid line indicates diagnosis of viral sepsis, pneumonia and influenza like symptoms in different shades of grey. Dashed line indicates diagnosis of MIS-C and neurological manifestations. Dotted line indicates other diagnosis.

with a viral infection or SARS-CoV-2 immune-mediated disease. Six out of 45 patients were admitted to Intensive Care Unit (ICU), none of them died.

Figure 2 reports the timeline distribution of the various patterns of presentation of our patients.

Figure 3 shows that the different patterns of presentation can be grouped based on the different timing of onset. All patients with viral sepsis, pneumonia and influenza-like symptoms (14 children) presented in the first month following the start of the local epidemic, dating February 23 (median time from the epidemic onset 20 days, IQR 15-27), and are classified as Group 1. Patients with a diagnosis of MIS-C or neurological manifestations (21 children) presented in the second and third month after the start of the epidemic (median time 59 days, IQR 51-66) and are classified as Group 2 (Group 1 vs. Group $2 p<0.001)$. The 10 patients with an incidentally positive NP/OP, admitted for conditions unrelated to COVID-19, were distributed evenly in the study period and are not included in this analysis (Figure 4). Data on all the patients are reported also in Table 1.

\section{Group 1: Patients Presenting in the Early Phase}

The first cluster presented at a median time from the start of the epidemic of 20 days (Interquartile range, IQR: 15-27) and comprised 14 children with viral sepsis (n. 7), pneumonia (n. 5), and influenza-like sdr (n. 2), of a median age of 1 year $(0,1-7)$ and a median weight of $21 \mathrm{~kg}(16.5-36)$. Eight were males (57\%) and 12 of Caucasian origin (86\%). All patients resulted NP/OP positive for SARS-coV-2. One of them performed a serology test that resulted positive 2 months after diagnosis. A positive history of contact with an affected family member was present in 10 of them $(71 \%)$. The median days of fever were three (2-5). Medians of the blood count values were, respectively: White blood cells

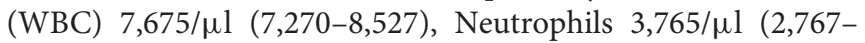
4,725), Lymphocytes 3,000/ $\mu \mathrm{l}(1,527-3,600)$, Haemoglobin ( $\mathrm{Hb})$

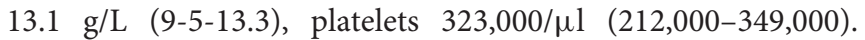
Median CRP was $0.9 \mathrm{mg} / \mathrm{dl}(0.25-8.9)$ and median procalcitonin was $0.16 \mathrm{ng} / \mathrm{ml}$ (0.11-0.51). Median LDH was $395 \mathrm{IU} / \mathrm{L}$ (356440), creatinine $0.34 \mathrm{mg} / \mathrm{dl}(0.2-0.4)$ and ALT $26 \mathrm{IU} / \mathrm{L}(20-$ 39). A chest X-ray was obtained in 10 patients and resulted positive in five with pneumonia and two with neonatal sepsis. Eight of 10 were treated with a course of intravenous antibiotics, three needed invasive respiratory support and one received antiviral therapy. Anti-inflammatory medications (steroid and hydroxychloroquine) were administered to 3 out of 14 patients.

\section{Group 2: Patients Presenting in the Late Phase}

The second group presented at a median time from the start of the epidemic of 59 days (51-66), and comprised 21 children with MIS-C (n. 18) and neurological manifestations (n. 3), of 


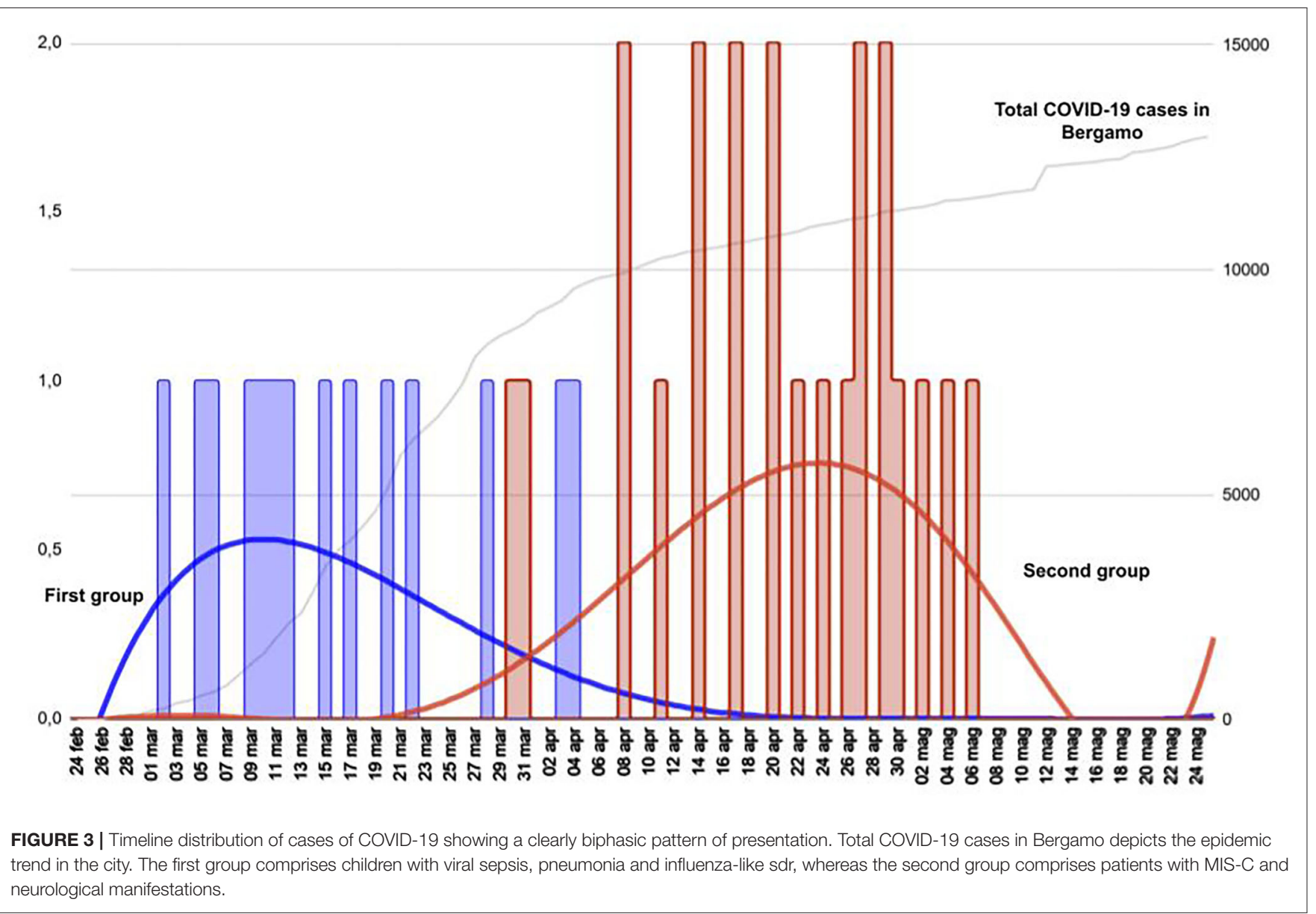

a median age of 8 years (5.4-11.5) and a median weight of $28 \mathrm{~kg}(17.6-53.5)$. Twelve were males (57\%), 18 of Caucasian origin $(86 \%)$. Nine patients had a SARS-CoV-2 positive NP/OP (43\%) and 12/21 (57\%) had a positive serology; two patients were positive for both. A positive history of contact with an affected family member was present in 12 of them (57\%). The duration of fever was a median of 6 days (5-7). The median of the blood count values were, respectively: WBC 9,610/ $\mu \mathrm{l}(7,280-12,730)$,

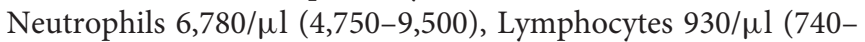

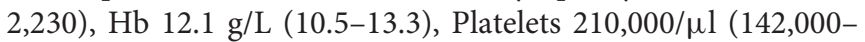
270,000). Other blood tests showed: CRP $16.6 \mathrm{mg} / \mathrm{dl}(12.9-25.7)$, procalcitonin $7.9 \mathrm{ng} / \mathrm{ml}$ (4.5-28.5), LDH $302 \mathrm{IU} / \mathrm{L}(240-424)$, creatinine $0.45 \mathrm{mg} / \mathrm{dl}(0.2-0.4)$ and ALT $24 \mathrm{IU} / \mathrm{L}(20-52)$. Chest X-ray was performed in 18 patients and tested positive in nine cases. Fifteen patients were treated with intravenous immunoglobulin (IVIG) and acetyl salicylate acid (ASA), 13 with steroids and 16 with an antibiotic course.

\section{Miscellaneous}

This group presented at a median time from the start of the epidemic of 42 days (20-67), and comprised 10 patients with a median age of 7 years (4-14) and a median weight of $24 \mathrm{Kg}$ (17-53). They were admitted for surgical, haematological or dermatological illnesses. Six were males $(60 \%)$ and 8 were of
Caucasian origin (80\%). All these patients had a positive NP/OP for SARS-CoV-2 and four of them had a history of contact with a intrafamiliar positive case. Median days of fever was two (0-3).

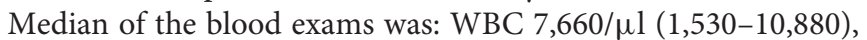

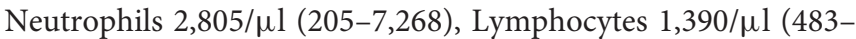
1,888), haemoglobin $10.3 \mathrm{~g} / \mathrm{L}(9.4-11.2)$, platelets $173,000 / \mu \mathrm{l}$ (50,000-269,000), CRP $0.15 \mathrm{mg} / \mathrm{dl}(0-1.2)$, LDH 317 IU/L (210435), creatinine $0.42 \mathrm{mg} / \mathrm{dl}(0.02-0.04)$ and ALT $29 \mathrm{IU} / \mathrm{L}$ (22-43) respectively. Three patients performed a chest X-ray, consistent with pneumonia in two of them. The third patient had a negative chest X-ray but performed a CT scan resulting positive for interstitial pneumonia.

\section{Comparison From Group 1 and Group 2}

A statistical analysis was carried out to compare Group 1 and Group 2, and data are summarized in Table 2.

Days of presentation after the start of the pandemic differed significantly from the two groups and was delayed in Group 2 $(p<0.001)$, as well as age that was older in Group $2(p=0.02)$. There was a significant difference for Neutrophil and platelet count, CRP and procalcitonin, that were all higher in Group 1. A significant difference was found also for Lymphocyte count, lower in Group 2. No significant differences were observed for renal and liver function, LDH levels and number of days of fever. 


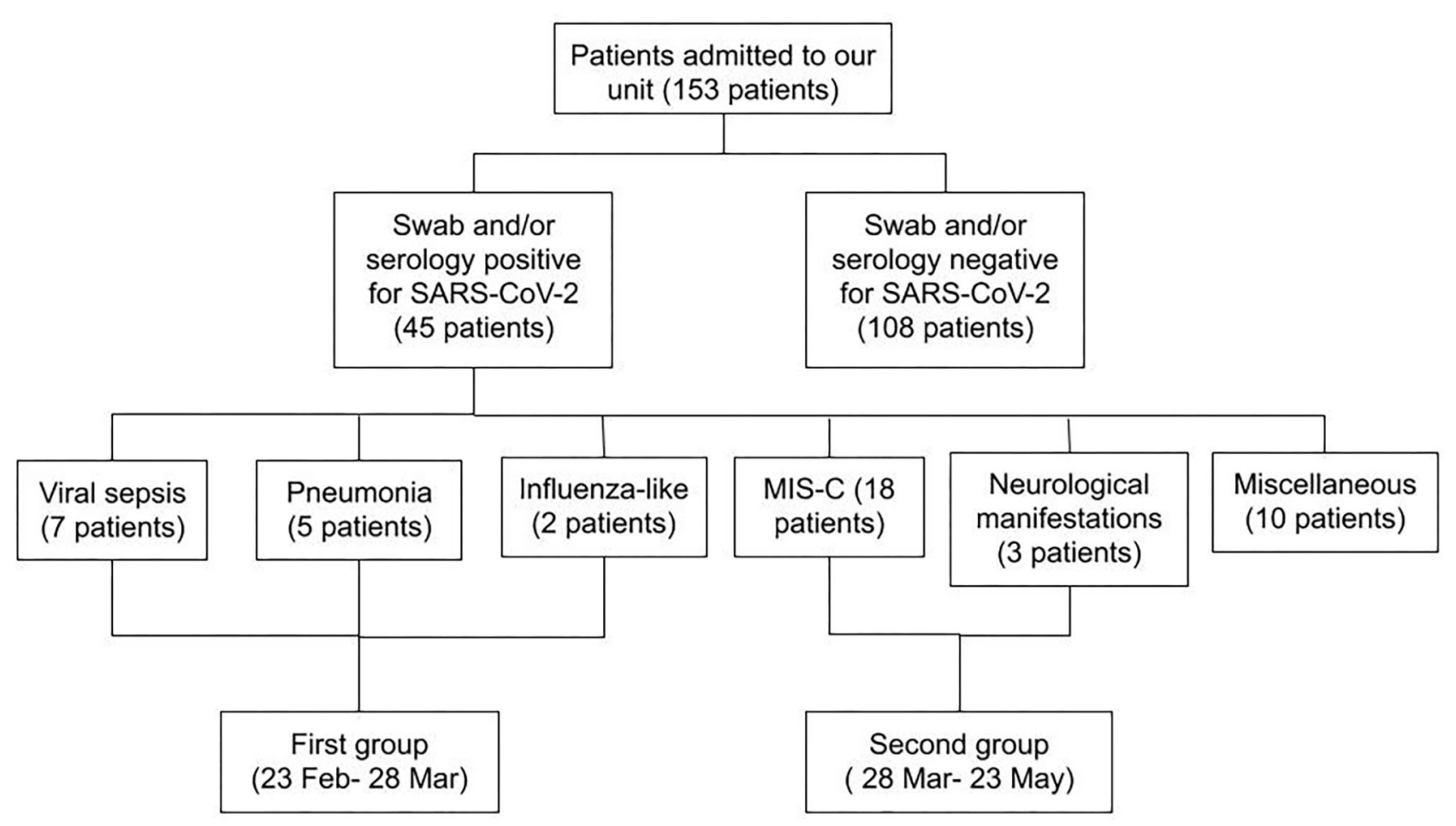

FIGURE 4 | Flow chart showing the features of all patients admitted during the study period. A first differentiation was made based on swab and serology results for SARS-CoV-2. Patients with a positive result of one or both tests were divided according to the pattern and the timing of presentation.

All patients in Group 1 had a positive swab sample for SARSCoV-2 against $43 \%$ in Group $2(P=<0.001)$. Serology was performed in one of Group 1 and was positive (other patients could not perform serology because it was not yet available at the moment), vs. 14 positive on 21 tested in Group 2. A history of contact with a COVID-19 case was present in 10/14 (71\%) of Group 1 vs. $12 / 21(57 \%)$ of Group $2(P=0.48)$.

\section{DISCUSSION}

The analysis of the first European centre hit by SARS-CoV2 pandemic may be advantageous in terms of understanding COVID-19 patterns of presentation in children. Indeed, the fact that at that time the local situation was not mitigated by containment measures and that a lockdown was adopted shortly thereafter makes this setting a reliable frame depicting the effects of SARS-CoV-2 free viral circulation. In this context, the timeline distribution (Figures 2, 3) of the diagnoses related to COVID19 revealed a biphasic pattern, well-distinguishable in terms of clinical presentation.

In the first phase of the epidemic, infants were admitted with patterns typical of an infectious disease: flu-like symptoms, pneumonia or viral sepsis. All these cases, called Group 1, are attributable to a mechanism of direct injury by SARS-CoV-2, with half of them presenting chest $\mathrm{X}$ ray lesions, and all of them having a positive NP/OP for SARS-CoV-2. Intriguingly this "infectious pattern" of presentation disappeared with social isolation measures. No case, with the same characteristics, has occurred since April 4 (in Italy the lockdown started on March 9).

The second group of patients, here referred to as Group 2, comprised 21 children: 18 with a diagnosis of MIS-C and three with neurological manifestations. Only $43 \%$ of patients presented a positive NP/OP for SARS-CoV-2, whereas the others had a positive serology. The statistical comparison between the two groups (Table 2) reveals a significant difference in blood cells count (neutrophils, lymphocytes and platelets) and in markers of inflammation (procalcitonin and CRP), suggesting a different pathophysiology of the disease. Remarkably, the first patient with a diagnosis of MIS-C was admitted on the $30^{\text {th }}$ of March while the first adult case of COVID-19 reported in the same region dates back to February 22.

SARS-CoV-2 infection in children usually presents a benign course, when compared to the adult population. All reports published so far show that children mostly present mild respiratory symptoms, with sporadic complications limited to people with comorbidities (11).

Patients admitted to our unit confirmed this impression. The patients with a more severe respiratory involvement had underlying comorbidities (Down syndrome and children with special health care needs). As already reported, several patients had some chest radiological abnormalities without showing any respiratory symptom (12). This data supports the tropism of SARS-CoV-2 for the respiratory tract also in asymptomatic patients $(3,13)$. 
TABLE 1 | Demographic and clinical features of all patients observed in the study period.

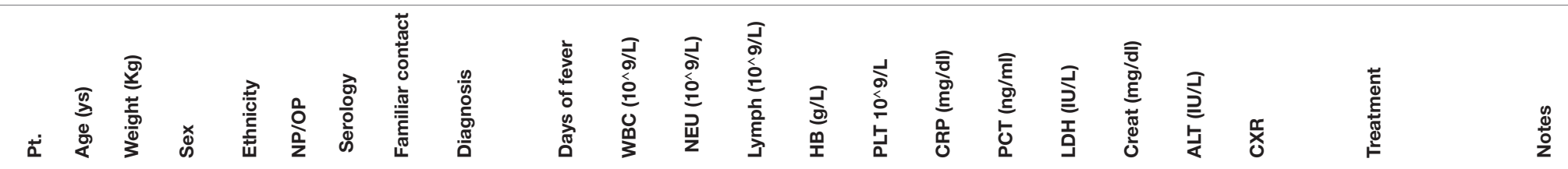

\begin{tabular}{|c|c|c|c|c|c|c|c|c|c|c|c|c|c|c|c|c|c|c|c|c|c|c|c|}
\hline \multirow[t]{14}{*}{ Group 1} & 1 & 0.1 & 3.4 & M & C & + & N/A & - & Sepsis & 3 & 7390 & 4030 & 1470 & 15.5 & 200 & 0.7 & 0.24 & 850 & 0.31 & 99 & $\begin{array}{l}\text { patchy } \\
\text { infiltrates }\end{array}$ & ATB & \\
\hline & 2 & 0.1 & 3.6 & $\mathrm{~F}$ & C & + & $\mathrm{N} / \mathrm{A}$ & - & Sepsis & 2 & 7910 & 2470 & 4170 & 13.8 & 278 & 0.5 & 0.05 & 440 & 0.26 & 20 & $\begin{array}{l}\text { Perihilar } \\
\text { opacities }\end{array}$ & ATB & \\
\hline & 3 & 0.1 & 4 & M & C & + & $\mathrm{N} / \mathrm{A}$ & + & Sepsis & 3 & 7230 & 3100 & 3600 & 8.9 & 726 & $<0,05$ & $<0.05$ & 310 & 0.31 & 27 & $\mathrm{~N} / \mathrm{A}$ & ATB & \\
\hline & 4 & 0.1 & 3.6 & M & C & + & $\mathrm{N} / \mathrm{A}$ & - & Sepsis & 0 & 11080 & 2670 & 5150 & 13.7 & 322 & 0.1 & 0.09 & 367 & 0.27 & 34 & Negative & $\mathrm{ATB}+\mathrm{HFO}$ & ICU admittance \\
\hline & 5 & 0.2 & 5.8 & $\mathrm{~F}$ & C & + & N/A & - & Sepsis & 4 & 7400 & 2400 & 3600 & 13.1 & 344 & 0.1 & 0.35 & 365 & 0.22 & 53 & $\mathrm{~N} / \mathrm{A}$ & ATB & \\
\hline & 6 & 0.2 & 3.8 & M & C & + & $\mathrm{N} / \mathrm{A}$ & + & Sepsis & 1 & 8050 & 2690 & 5200 & 10.3 & 340 & 0.2 & 0.15 & 318 & 0.21 & 33 & $\mathrm{~N} / \mathrm{A}$ & ATB & \\
\hline & 7 & 0.1 & 4.9 & $\mathrm{~F}$ & SA & + & N/A & + & Sepsis & 5 & 8620 & 4500 & 3000 & 11.5 & 622 & 0.3 & 3.45 & 402 & 0.2 & 19 & $\mathrm{~N} / \mathrm{A}$ & ATB & \\
\hline & 8 & 14.7 & 80 & $\mathrm{~F}$ & C & + & + & + & pneumonia & 15 & 7440 & 6570 & 500 & 13.3 & 166 & 15.1 & 0.6 & 721 & 1.35 & 41 & $\begin{array}{l}\text { Perihilar } \\
\text { opacities }\end{array}$ & $\begin{array}{l}\text { CPAP, IOT, ATB, } \\
\text { heparin }\end{array}$ & ICU admittance \\
\hline & 9 & 6.6 & 19 & $\mathrm{~F}$ & C & + & $\mathrm{N} / \mathrm{A}$ & + & pneumonia & 5 & 5390 & 3500 & 1200 & 4.6 & 189 & 6.8 & & 216 & 1.36 & 9 & $\begin{array}{l}\text { Perihilar } \\
\text { opacities }\end{array}$ & ATB, NIV & \\
\hline & 10 & 9.7 & 35 & F & As & + & N/A & + & pneumonia & 14 & 6740 & 4800 & 1080 & 9.5 & 179 & 11 & 0.71 & 415 & 0.7 & 14 & $\begin{array}{l}\text { Lobar } \\
\text { pneumonia, } \\
\text { pleural } \\
\text { effusion }\end{array}$ & ATB. Steroid & Mycoplasma + \\
\hline & 11 & 4 & 14 & M & C & + & N/A & + & pneumonia & 0 & 14140 & 9690 & 3490 & 13.3 & 351 & 0.05 & & 353 & 0.38 & 20 & $\begin{array}{l}\text { Lobar } \\
\text { pneumonia }\end{array}$ & ATB. Steroid & Parainfluenzae + \\
\hline & 12 & 14.7 & 37 & M & C & + & N/A & + & pneumonia & 6 & 8250 & 4240 & 2690 & 13.2 & 449 & 0.9 & 1.6 & 438 & 0.42 & 47 & $\begin{array}{l}\text { Perihilar } \\
\text { opacities }\end{array}$ & $\begin{array}{l}\text { NIV, antiviral, } \\
\text { hydroxicloroquine, } \\
\text { ATB }\end{array}$ & CKD \\
\hline & 13 & 7.2 & 21 & M & C & + & $\mathrm{N} / \mathrm{A}$ & + & $\begin{array}{l}\text { influenza- } \\
\text { like }\end{array}$ & 3 & 5800 & 3000 & 1700 & 13.5 & 250 & 0.1 & 0.13 & 631 & 0.44 & 24 & Negative & NSAID & $\begin{array}{l}\text { Metapneumovirus } \\
+, \text { ICU } \\
\text { admittance }\end{array}$ \\
\hline & 14 & 1.1 & 11.8 & M & C & + & N/A & + & $\begin{array}{l}\text { influenza- } \\
\text { like }\end{array}$ & 2 & 9360 & 5850 & 3000 & 10.7 & 324 & 0.4 & 0.42 & 387 & 0.29 & 24 & Negative & NSAID & \\
\hline \multirow[t]{4}{*}{ Group 2} & 15 & 7 & 45 & M & C & + & + & + & MIS-C & 7 & 12730 & 11260 & 1000 & 13.4 & 130 & 30 & 59 & 729 & 0.8 & 79 & $\begin{array}{l}\text { Perihilar } \\
\text { opacities }\end{array}$ & $\begin{array}{l}\text { ATB, IVIG, ASA, } \\
\text { steroid }\end{array}$ & Meningeal signs \\
\hline & 16 & 2.9 & 13.9 & $\mathrm{~F}$ & C & - & + & - & MIS-C & 6 & 4480 & 3250 & 860 & 11 & 116 & 12.2 & 6.6 & 424 & 0.28 & 46 & $\begin{array}{l}\text { Perihilar } \\
\text { opacities }\end{array}$ & $\begin{array}{l}\text { ATB, IVIG, ASA, } \\
\text { steroid }\end{array}$ & \\
\hline & 17 & 7.6 & 31.8 & $\mathrm{~F}$ & C & + & + & + & MIS-C & 8 & 10260 & 9150 & 670 & 13.3 & 228 & 52.5 & 7.57 & 1057 & 0.5 & 78 & Negative & $\begin{array}{l}\text { ATB, IVIG, ASA, } \\
\text { steroid }\end{array}$ & $\begin{array}{l}\text { Cardiogenic } \\
\text { shock, ICU } \\
\text { admittance }\end{array}$ \\
\hline & 18 & 5 & 23 & M & C & - & + & + & MIS-C & 8 & 6470 & 4750 & 1200 & 12.1 & 206 & 12.7 & & 301 & 0.42 & 21 & Negative & $\begin{array}{l}\text { ATB, IVIG, ASA, } \\
\text { steroid }\end{array}$ & Meningeal signs \\
\hline
\end{tabular}




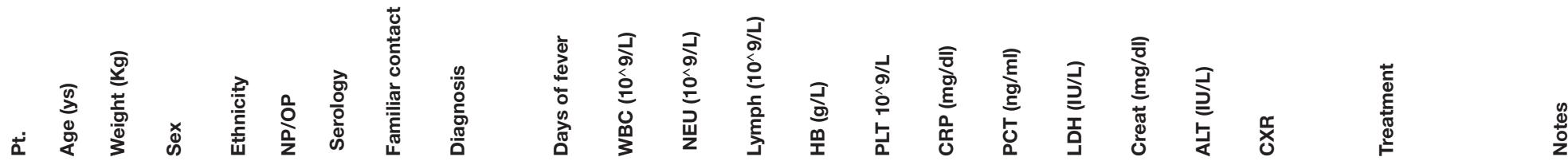

\begin{tabular}{|c|c|c|c|c|c|c|c|c|c|c|c|c|c|c|c|c|c|c|c|c|c|c|}
\hline 19 & 5.5 & 16.5 & $M$ & C & - & + & + & MIS-C & 8 & 7280 & 6060 & 740 & 12.6 & 179 & 15 & & 318 & 0.44 & 20 & Negative & $\begin{array}{l}\text { ATB, IVIG, ASA, } \\
\text { steroid }\end{array}$ & \\
\hline 20 & 9.3 & 29 & M & SA & - & + & - & MIS-C & 10 & 16710 & 14810 & 860 & 11.1 & 210 & 24.2 & 27 & 302 & 1.02 & 63 & $\begin{array}{l}\text { Lobar } \\
\text { pneumonia }\end{array}$ & $\begin{array}{l}\text { ATB, IVIG, ASA, } \\
\text { steroid, diuretic }\end{array}$ & $\begin{array}{l}\text { Cardiogenic } \\
\text { shock }\end{array}$ \\
\hline 21 & 2.6 & 12 & F & C & + & N/A & + & MIS-C & 5 & 12220 & 5660 & 3700 & 10.6 & 250 & 15 & 5.04 & 314 & 0.23 & 18 & Negative & ASA & \\
\hline 22 & 5.4 & 16.5 & $M$ & C & - & + & + & MIS-C & 7 & 4660 & 3860 & 460 & 9.3 & 142 & 12.2 & 10.4 & 219 & 0.3 & 20 & $\begin{array}{l}\text { Lobar } \\
\text { pneumonia }\end{array}$ & $\begin{array}{l}\text { ATB, IVIG, ASA, } \\
\text { steroid, heparin }\end{array}$ & $\begin{array}{l}\text { Cardiogenic } \\
\text { shock }\end{array}$ \\
\hline 23 & 6.9 & 25 & $\mathrm{~F}$ & Afr & + & $\mathrm{N} / \mathrm{A}$ & - & MIS-C & 6 & 23120 & 19559 & 1600 & 11.4 & 237 & 37.3 & 64 & 642 & 0.27 & 22 & $\begin{array}{l}\text { Perihilar } \\
\text { opacities }\end{array}$ & $\begin{array}{l}\text { ATB, IVIG, ASA, } \\
\text { steroid, heparin }\end{array}$ & $\begin{array}{l}\text { Cardiogenic } \\
\text { shock, ICU } \\
\text { admittance }\end{array}$ \\
\hline 24 & 1.2 & 10.6 & $\mathrm{~F}$ & C & - & + & - & MIS-C & 7 & 20140 & 11000 & 4480 & 9.9 & 795 & 20 & & 550 & 0.18 & 29 & $\begin{array}{l}\text { Perihilar } \\
\text { opacities }\end{array}$ & $\begin{array}{l}\text { ATB, IVIG, ASA, } \\
\text { steroid }\end{array}$ & \\
\hline 25 & 17.2 & 70 & M & SA & - & + & - & MIS-C & 5 & 7980 & 6780 & 760 & 15.2 & 237 & 15.6 & & 240 & 1.28 & 21 & Negative & ASA, ATB & \\
\hline 26 & 9.2 & 29 & M & C & + & $\mathrm{N} / \mathrm{A}$ & + & MIS-C & 6 & 12140 & 9000 & 520 & 13.3 & 142 & 26.7 & 8.2 & 269 & 0.5 & 56 & $\begin{array}{l}\text { Lobar } \\
\text { pneumonia }\end{array}$ & $\begin{array}{l}\text { ATB, IVIG, ASA, } \\
\text { steroid, diuretic }\end{array}$ & \\
\hline 27 & 6 & 18 & M & C & - & + & + & MIS-C & 5 & 8810 & 6700 & 870 & 11.1 & 132 & 26.2 & 18.1 & 444 & 0.31 & 63 & Negative & $\begin{array}{l}\text { ATB, IVIG, ASA, } \\
\text { steroid, diuretic, } \\
\text { inotropes }\end{array}$ & $\begin{array}{l}\text { Cardiogenic } \\
\text { shock, ICU } \\
\text { admittance }\end{array}$ \\
\hline 28 & 7.6 & 22 & $M$ & C & - & + & + & MIS-C & 8 & 19340 & 15700 & 2230 & 10.1 & 389 & 17.6 & 2.64 & 221 & 0.46 & 52 & Negative & IVIG, ASA, ATB & $\begin{array}{l}\text { Cardiogenic } \\
\text { shock }\end{array}$ \\
\hline 29 & 11.6 & 69 & M & C & - & + & + & MIS-C & 5 & 9900 & 7800 & 610 & 12.1 & 203 & 30.5 & 2.11 & 302 & 0.4 & 24 & $\begin{array}{l}\text { Perihilar } \\
\text { opacities }\end{array}$ & $\begin{array}{l}\text { ATB, IVIG, ASA, } \\
\text { steroid, diuretic }\end{array}$ & $\begin{array}{l}\text { Cardiogenic } \\
\text { shock }\end{array}$ \\
\hline 30 & 1.8 & 10.4 & $\mathrm{~F}$ & C & - & + & - & MIS-C & 5 & 13720 & 9500 & 2730 & 9.6 & 358 & 9.6 & 2.87 & 248 & 0.28 & 19 & $\begin{array}{l}\text { Lobar } \\
\text { pneumonia }\end{array}$ & IVIG, ASA, ATB & \\
\hline 31 & 8.3 & 27 & $\mathrm{~F}$ & C & + & $N / A$ & + & MIS-C & 4 & 5540 & 4400 & 430 & 10 & 78 & 13.5 & 32.8 & 342 & 0.46 & 34 & $\begin{array}{l}\text { Perihilar } \\
\text { opacities } \\
\text { and } \\
\text { pleural } \\
\text { effusion }\end{array}$ & $\begin{array}{l}\text { ATB, IVIG, ASA, } \\
\text { steroid }\end{array}$ & \\
\hline 32 & 16.4 & 52 & $\mathrm{~F}$ & C & + & $\mathrm{N} / \mathrm{A}$ & - & MIS-C & 3 & 9610 & 7540 & 930 & 12.3 & 270 & 18 & & 137 & 0.59 & 13 & Negative & & \\
\hline 33 & 17.8 & 70 & M & C & - & + & + & encephalitis & 2 & 4080 & 1800 & 1730 & 15.4 & 201 & 0 & & 305 & 1.28 & 16 & $\mathrm{~N} / \mathrm{A}$ & $\begin{array}{l}\text { ATB, antiviral } \\
\text { agent, NSAID }\end{array}$ & \\
\hline 34 & 16.3 & 58 & M & C & + & $\mathrm{N} / \mathrm{A}$ & - & epilepsy & 0 & 8510 & 5770 & 2340 & 15 & 320 & 0.05 & & 203 & 1.09 & 27 & N/A & & \\
\hline 35 & 12.5 & 79 & $\mathrm{~F}$ & C & + & N/A & - & $\| \mathrm{H}$ & 0 & 7930 & 3760 & 3400 & 12.5 & 289 & 0.3 & & 215 & 0.55 & 23 & N/A & diuretic & \\
\hline
\end{tabular}


TABLE 1 | Continued

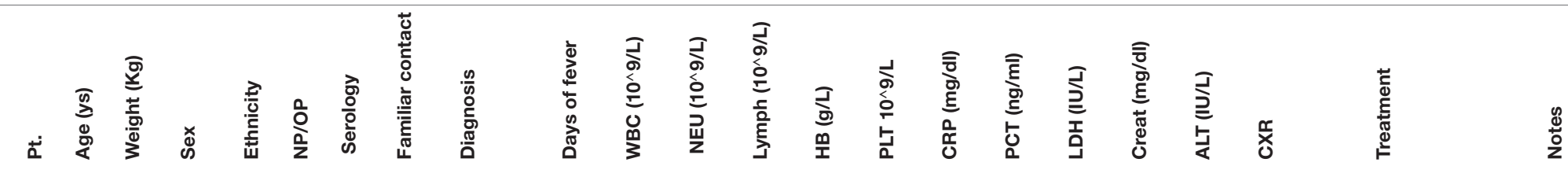

\begin{tabular}{|c|c|c|c|c|c|c|c|c|c|c|c|c|c|c|c|c|c|c|c|c|c|c|}
\hline \multirow[t]{10}{*}{ Others } & 36 & 0.4 & 5.4 & F & C & + & N/A & - & $\begin{array}{l}\text { Solid } \\
\text { tumor }\end{array}$ & 3 & 330 & 110 & 210 & 11.1 & 75 & 10.3 & & 453 & 0.20 & 21 & $\begin{array}{l}\text { Lobar } \\
\text { pneumonia }\end{array}$ & ATB \\
\hline & 37 & 6.5 & 17.1 & M & C & + & N/A & - & $\begin{array}{l}\text { Solid } \\
\text { tumor }\end{array}$ & 0 & 11220 & 10330 & 730 & 9.4 & 316 & 0.3 & & 260 & 0.26 & 48 & $\mathrm{~N} / \mathrm{A}$ & chemotherapy \\
\hline & 38 & 14.5 & 58.5 & $\mathrm{~F}$ & C & + & $\mathrm{N} / \mathrm{A}$ & - & $\begin{array}{l}\text { Solid } \\
\text { tumor }\end{array}$ & 7 & 630 & 220 & 400 & 9.5 & 25 & 1.5 & & 167 & 1.13 & 31 & $\begin{array}{l}\text { Perihilar } \\
\text { opacities }\end{array}$ & $\begin{array}{l}\text { chemotherapy, } \\
\text { ATB, G-CSF }\end{array}$ \\
\hline & 39 & 11.2 & 43 & M & C & + & N/A & + & Appendicitis & 1 & 9860 & 8110 & 980 & 13.9 & 184 & 0.6 & & 251 & 0.54 & 27 & $\mathrm{~N} / \mathrm{A}$ & ATB \\
\hline & 40 & 15.4 & 60 & M & C & + & N/A & - & Appendicitis & 2 & 13230 & 10790 & 1800 & 14.5 & 230 & 0.2 & & 196 & 0.57 & 32 & N/A & ATB \\
\hline & 41 & 16.4 & 56 & M & C & + & N/A & + & Vasculitis & 0 & 4230 & 1670 & 1900 & 14.5 & 162 & 0 & & 146 & 1.25 & 17 & N/A & NSAID \\
\hline & 42 & 3.2 & 17.3 & $\mathrm{~F}$ & C & + & N/A & - & Leukemia & 3 & 370 & 30 & 320 & 8.4 & 42 & 0 & & 381 & 0.22 & 181 & $\mathrm{~N} / \mathrm{A}$ & ATB \\
\hline & 43 & 3.3 & 15 & $M$ & Afr & + & N/A & + & $\begin{array}{l}\text { Eye } \\
\text { trauma }\end{array}$ & 0 & 7530 & 4740 & 1850 & 9.3 & 591 & $<0.05$ & & 478 & 0.28 & 23 & $\mathrm{~N} / \mathrm{A}$ & \\
\hline & 44 & 6.9 & 24 & $M$ & Afr & + & N/A & - & $\begin{array}{l}\text { Solid } \\
\text { tumor }\end{array}$ & 0 & 7790 & 3940 & 3030 & 11.2 & 282 & 0 & & 373 & 0.37 & 47 & $\mathrm{~N} / \mathrm{A}$ & surgery \\
\hline & 45 & 7.9 & 23 & F & C & + & N/A & + & Leukemia & 5 & 40010 & 200 & 21800 & 8.5 & 8 & 7.7 & 1.16 & 628 & 0.48 & 20 & $\begin{array}{l}\text { Perihilar } \\
\text { opacities }\end{array}$ & $\begin{array}{l}\text { chemotherapy, } \\
\text { steroid }\end{array}$ \\
\hline
\end{tabular}

Pt, patient; ys, years; Kg, kilograms; NP/OP, nasopharyngeal/oropharingeal swab; WBC, white blood cells (n.v. 6,000-17,000 10^9/L); Neu, neutrophils (n.v. 1,500-9,000 10^9/L); Lymph, lymphocytes (n.v. 3,000-10,000 10^9/L): HB, hemoglobin (n.v. 12-14 g/L): PLT, platelets (n.v. 150-400 10^9/L): CRP, C-reactive protein (n.v. 0-1.0 mg/dl): PCT, procalcitonine (n.v. < 0.05 ng/ml); LDH, lactate dehydrogenase (n.v. 120-246 IU/L): Creatm, creatinine (n.v. $0.1-0.7$ mg/dl); ALT, alanine aminotransferase (n.v. 7-40 IU/L); CXR, chest X-ray; M, male; F, female; C, Caucasian; SA, South American; As, Asian; Afr, African; N/A, not available; MIS-C, multisystem inflammatory syndrome in $0.1-0.7 \mathrm{mg} / \mathrm{dll})$; ALT, alanine aminotransferase (n.V. 7-4O IU/L); CXR, chest X-ray; M, male; F, female; C, Caucasian; SA, South American; As, Asian; Afr, African; N/A, not available; MIS-C, multisystem inflammatory syndrome in
children; IIH, idiopathic intracranial hypertension; ATB, antibiotic; HFO, high flow oxygen; ICU, intensive care unit; CPAP, continuous positive airway pressure; IOT, orotracheal intubation; NIV, non-invasive ventilation; NSAID, non-steroidal anti-inflammatory drug; IVIG, intravenous immunoglobulin; ASA, acetylsalicylic acid; CKD, chronic kidney disease; G-CSF, granulocyte colony stimulation factor. 
TABLE 2 | Comparison between the two groups of patients diagnosed with SARS-CoV-2 infection cases.

\begin{tabular}{|c|c|c|c|}
\hline & Group 1 (n 14) & Group 2 (n 21) & $P$ \\
\hline Presentation after the start of the pandemic (days) & $20(15-27)$ & $59(51-66)$ & $<0.001$ \\
\hline Age (years) & $1(0.1-7)$ & $8(5.4-11.5)$ & 0.02 \\
\hline $\operatorname{Sex}(M / F)$ & $8 / 6$ & $12 / 9$ & 1 \\
\hline Weight (Kilograms) & $21(16.5-36)$ & $28(17.6-53.5)$ & 0.57 \\
\hline Affected family member & $10 / 14(71 \%)$ & $12 / 21(57 \%)$ & 0.48 \\
\hline Positive swab sample & $14 / 14(100 \%)$ & $9 / 21(43 \%)$ & $<0.001$ \\
\hline Positive serology & $1 / 1$ & $14 / 21(67 \%)$ & - \\
\hline Fever duration (days) & $3(2-5)$ & $6(5-7)$ & 0.42 \\
\hline 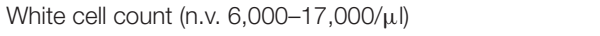 & $7,675(7,270-8,527)$ & $9,610(7,280-12,730)$ & 0.1 \\
\hline Neutrophil count (n.v. 1,500-9,000/ $\mu \mathrm{l}$ ) & $3,765(2,767-4,725)$ & $6,780(4,750-9,500)$ & 0.006 \\
\hline 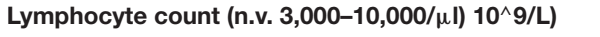 & $3,000(1,527-3,600)$ & $930(740-2,230)$ & 0.006 \\
\hline Haemoglobin (n.v. 12-14 g/L) & $13.1(9.5-13.3)$ & $12.1(10.5-13.3)$ & 0.3 \\
\hline Platelet count (n.v. 150-400/ml) & $323(212-349)$ & $210(142-270)$ & 0.009 \\
\hline CRP (n.v. 0-1.0 mg/dl) & $0.9(0.25-8.9)$ & $16.6(12.9-25.7)$ & 0.008 \\
\hline Procalcitonin (n.v. $<0.05 \mathrm{ng} / \mathrm{ml}$ ) & $0.16(0.11-0.51)$ & $7.9(4.5-28.5)$ & 0.008 \\
\hline LDH (n.v. 120-246 IU/L) & 395 (356-440) & $302(240-424)$ & 0.30 \\
\hline ALT (n.v. 7-40 IU/L) & $26(20-39)$ & $24(20-52)$ & 0.76 \\
\hline Creatinine (n.v. 0.1-0.7 mg/dl) & $0.34(0.2-0.4)$ & $0.45(0.2-0.4)$ & 0.34 \\
\hline Chest $X$ ray performed & $71 \%$ & $86 \%$ & - \\
\hline ICU admittance & $3 / 14$ (21\%) & $3 / 21(14 \%)$ & 0.66 \\
\hline
\end{tabular}

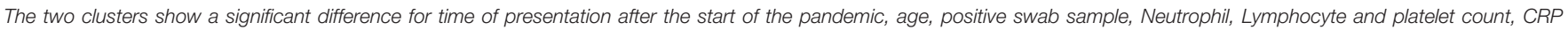

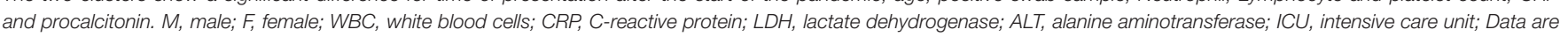
reported as medians and interquartile range (IQR).

Bold values evidence significative statistical differences between the two groups.

The different expression of angiotensin converting enzyme2 (ACE-2) receptor in children and adults has been advocated as one of the factors implicated in the reduced morbidity of SARS-CoV-2 observed at young ages $(14,15)$. ACE- 2 is a counterregulatory enzyme of the renin-angiotensin-system acting by converting angiotensin-2 to Ang-(1-7) form. Upregulation of the angiotensin-2 axis leads to pro-inflammatory effects in the respiratory and cardiovascular systems (16). After entering pneumocytes, SARS-CoV-2 downregulates ACE-2 expression, decreasing angiotensin-2 metabolism. In children a reduced expression of ACE-2 receptor in upper airways may be protective against COVID-19, leading to less severe disease (17).

Sepsis-like presentation in neonates, already reported in literature $(18,19)$, can be explained by the characteristics of immunity in the first phases of life. Infants present an immature B lymphocyte and Th1 and Th2 response, but harbor a high level of Tregs. The innate immune response represents the first line of protection against SARS-CoV-2, but in case of dysregulation of such response, more typical of older age, this can result in an excessive inflammation leading to a severe disease and even death (20).

Patients with COVID-19 tend to present lymphopenia and high biomarkers of inflammation (21). These findings are prominent in Group 2 of our study, differing significantly from Group 1. Intriguingly these groups differ also by age. The agerelated evolution of the immune system can play a role in this difference (22).
The pathophysiology of severe COVID-19 in adults follows different phases of injury with a first phase of infection, usually characterized by direct lung damage, followed by an inflammatory reaction known as "cytokine storm," causing a rapid clinical deterioration $(23,24)$. Such condition seems to be different in children. After the onset of the epidemic worldwide, there have been several reports of increased incidence of Kawasaki-like disease cases $(25,26)$. The Center for Disease Control and Prevention and the World Health Organization proposed a new diagnostic framework, called multisystemic inflammatory syndrome associated to COVID-19 in children (10, 27). The first published case series comes from our experience in the Bergamo province (26).

After the first report of 10 cases, we analyzed 18 patients meeting the criteria for MIS-C. In this setting SARS-CoV-2 may act as a superantigen cascading macrophages and complement recruitment, leading to a sort of "cytokine storm" $(23,28,29)$. In adults, the inflammatory cascade seems to be activated in 2-3 weeks $(30,31)$. All our patients with MIS-C presented in the second and third month (Figures 2, 3) of the epidemic, suggesting that activation latency in children may be longer.

Neurological symptoms associated with SARS-CoV-2 exposure have been reported in adults (32) and in children $(33,34)$. Some of these symptoms appear to be the consequence of direct viral invasion of the nervous system tissue, others arise as a post viral autoimmune process, or are the result of metabolic and systemic complications due to the associated critical illness 
(32). Our analysis found three patients with mixed neurological manifestations and two patients with MIS-C and meningeal signs, in the second phase of the epidemic, suggesting a post viral autoimmune process as the cause of the clinical picture.

In the described cohort almost all pediatric ages are represented but clusters are detectable in infants, toddlers and in school age. All cases presenting in infants belong to the pattern of viral sepsis, while patients with respiratory symptoms tend to be toddlers or in school age. MIS-C and neurological patients, presenting in school age, suggest a relationship between immune system maturity and autoimmune complications.

Multicenter studies confirm COVID-19 infection is differently expressed in different pediatric age groups. Infants under 1 year of age represent $29 \%$ of infected pediatric patients (7\% under 1 month of age), $10 \%$ between 1 and 2 years, $11 \%$ between 2 and 5 years, $16 \%$ between 5 and 10 years and $34 \%$ over 10 years (35). The hospitalization rate in the pediatric population is around eight per 100,000 (36). Our Covid-19 pediatric area was the only one in a region of about 300,000 pediatric subjects, suggesting a hospitalization rate of 15 out of 100,000. This data suggests the relevance of our analysis in a period of free viral circulation with more than $50 \%$ of the population demonstrating antibodies for SARS-CoV-2 (2).

A direct comparison of our series with others is rather difficult given the small number of cases compared to other far more numerous series and substantially confirms already published data (8). Despite this, the distinctiveness of the context allows to highlight the most frequent hospital clinical pictures in the child with their temporal distribution.

A Korean single-center study described clinical features and persistence of viral RNA in 91 infants hospitalized after detection of SARS-CoV-2, regardless of their clinical pattern. No MIS-C cases appears in this series and symptomatic patients presented respiratory or influenza-like symptoms confirming our observation (37). The average persistence of viral RNA oscillated between 18 and 20 days regardless of the reported symptoms confirming as a positive swab sample in our MIS-C cases was compatible with an infection of three or more weeks earlier (37).

In conclusion, the analysis of children presenting at the first epicentre of European SARS-CoV-2 epidemic, at a time when health care measures aimed at mitigating its diffusion were not in place, allowed us to recognize a dual pattern of disease, related to a different pathophysiology of injury. The distinctive

\section{REFERENCES}

1. Available online at: http://www.salute.gov.it/portale/nuovocoronavirus/ dettaglioContenutiNuovoCoronavirus.jsp?lingua=english\&id=5367\&area $=$ nuovoCoronavirus\&menu=vuoto (accessed November 9, 2020).

2. Regione_Lombardia. Coronavirus: i dati dei test sierologici effettuati nella Bergamasca dal 23 aprile al 3 giugno (2020) Available online at: http:// www.ats-bg.it/upload/asl_bergamo/gestionedocumentale/CSATSBG202006-08coronavirusesitisierologici_784_31055.pdf (accessed June 15, 2020).

3. Zheng F, Liao C, Fan QH, Chen H-B, Zhao X-G, Xie Z-G, et al. Clinical characteristics of children with coronavirus disease 2019 in Hubei, China. Curr Med Sci. (2020) 40:275-80. doi: 10.1007/s11596-0202172-6 immune response that children mount against the virus seems to have paramount importance in this battle, and understanding its deepest features will probably contribute to an effective management of patients with COVID-19.

\section{DATA AVAILABILITY STATEMENT}

The original contributions presented in the study are included in the article/Supplementary Material further inquiries can be directed to the corresponding author/s.

\section{ETHICS STATEMENT}

The studies involving human participants were reviewed and approved by Bergamo Ethics Committee. Written informed consent to participate in this study was provided by the participants' legal guardian/next of kin.

\section{AUTHOR'S NOTE}

Infection by SARS-CoV-2, named COVID-19, spread worldwide since the end of 2019 and Bergamo was one of the most affected areas in Europe. Following the first outbreak, more than half of the population of the Bergamo province had been infected, unfortunately becoming a model of the impact of COVID19 epidemic on people's health. COVID-19 presents different patterns of clinical presentation in adults and children. In adults, the clinical picture is dominated by interstitial pneumonia possibly complicated by cardiovascular involvement. In children the clinical presentation is mild, mostly with an influenza-like pattern; serious cases are rare and full recovery is the rule. We performed an analysis of clinical patterns of paediatric patients admitted to our unit during the first three months of the outbreak. The peculiarity of our epidemiological situation can add new insights in characteristics of SARS-CoV-2 infection in children, following a period of unmitigated viral circulation. An immunological discussion is provided to fournish possible explanations about differences with adult patterns of the disease.

\section{AUTHOR CONTRIBUTIONS}

All authors listed have made a substantial, direct and intellectual contribution to the work, and approved it for publication.
4. Akhmerov A, Marbán E. COVID-19 and the Heart. Circ Res. (2020) 126:144355. doi: 10.1161/CIRCRESAHA.120.317055

5. Patel NA. Pediatric COVID-19: systematic review of the literature. Am J Otolaryngol. (2020) 41:102573. doi: 10.1016/j.amjoto.2020.102573

6. L'Huillier AG, Asner SA. COVID-19: impact pédiatrique [pediatric impact of COVID-19]. Rev Med Suisse. (2020) 16:839-41.

7. Nicastro E, Mazza A, Gervasoni A, Di Giorgio A, D’Antiga L. A pediatric emergency department protocol to avoid intrahospital spread of SARSCoV-2 during the outbreak in Bergamo, Italy. J Pediatr. (2020) 222:231-5. doi: 10.1016/j.jpeds.2020.04.026

8. Hoang A, Chorath K, Moreira A, Evans M, Burmeister-Morton F, Burmeister F, et al. COVID-19 in 7780 pediatric patients: a systematic review. EClinicalMedicine. (2020) 24:100433. doi: 10.1016/j.eclinm.2020.100433 
9. Goldstein B, Giroir B, Randolph A. International Consensus Conference on Pediatric Sepsis. International pediatric sepsis consensus conference: definitions for sepsis and organ dysfunction in pediatrics. Pediatr Crit Care Med. (2005) 6:2-8. doi: 10.1097/01.PCC.0000149131.72248.E6

10. Available online at: http://publichealth.lacounty.gov/eprp/lahan/alerts/ CDCMISC051420.pdf (accessed June 15, 2020).

11. Parri N, Lenge $M$, Buonsenso $D$; Coronavirus infection in pediatric emergency departments (confidence) research group. Children with Covid-19 in pediatric emergency departments in Italy. N Engl J Med. (2020) 383:187-90. doi: 10.1056/NEJMc2007617

12. Li W, Cui H, Li K, Fang Y, Li S. Chest computed tomography in children with COVID-19 respiratory infection. Pediatr Radiol. (2020) 50:796-9. doi: 10.1007/s00247-020-04656-7

13. Xia W, Shao J, Guo Y, Peng X, Li Z, Hu D. Clinical and CT features in pediatric patients with COVID-19 infection: different points from adults. Pediatr Pulmonol. (2020) 55:1169-74. doi: 10.1002/ppul.24718

14. South AM, Brady TM, Flynn JT. ACE2 (angiotensin-converting enzyme 2), COVID-19, and ACE inhibitor and Ang II (Angiotensin II) receptor blocker use during the pandemic: the pediatric perspective. Hypertension. (2020) 76:16-22. doi: 10.1161/HYPERTENSIONAHA.120.15291

15. Dhochak N, Singhal T, Kabra SK, Lodha R. Pathophysiology of COVID-19: why children fare better than adults?. Indian J Pediatr. (2020) 87:537-46. doi: 10.1007/s12098-020-03322-y

16. Dalan R, Bornstein SR, El-Armouche A, Rodionov RN, Markov A, Wielockx B, et al. The ACE-2 in COVID-19: foe or friend? Horm Metab Res. (2020) 52:257-63. doi: 10.1055/a-1155-0501

17. Bunyavanich S, Do A, Vicencio A. Nasal gene expression of angiotensinconverting enzyme 2 in children and adults. JAMA. (2020) 323:2427-9. doi: 10.1001/jama.2020.8707

18. Dumpa V, Kamity R, Vinci AN, Noyola E, Noor A. Neonatal coronavirus 2019 (COVID-19) Infection: a case report and review of literature. Cureus. (2020) 12:e8165. doi: 10.7759/cureus. 8165

19. Ng KF, Bandi S, Bird PW, Wei-Tze Tang J. COVID-19 in Neonates and infants: progression and recovery. Pediatr Infect Dis J. (2020) 39:e140-2. doi: 10.1097/INF.0000000000002738

20. Shaw AC, Goldstein DR, Montgomery RR. Age-dependent dysregulation of innate immunity. Nat Rev Immunol. (2013) 13:875-87. doi: 10.1038/nri3547

21. Qin C, Zhou L, Hu Z, Zhang S, Yang S, Tao Y, et al. Dysregulation of immune response in patients with coronavirus 2019 (COVID-19) in Wuhan, China. Clin Infect Dis. (2020) 71:762-8. doi: 10.1093/cid/ciaa248

22. Vardhana SA, Wolchok JD. The many faces of the anti-COVID immune response. J Exp Med. (2020) 217:e20200678. doi: 10.1084/jem.20200678

23. Ye Q, Wang B, Mao J. The pathogenesis and treatment of the cytokine storm in COVID-19. J Infect. (2020) 80:607-13. doi: 10.1016/j.jinf.2020.03.037

24. Felsenstein S, Herbert JA, McNamara PS, Hedrich CM. COVID-19: immunology and treatment options. Clin Immunol. (2020) 215:108448. doi: 10.1016/j.clim.2020.108448

25. Toubiana J, Poirault C, Corsia A, Bajolle F, Fourgeaud J, Angoulvant F, et al. Kawasaki-like multisystem inflammatory syndrome in children during the covid-19 pandemic in Paris, France: prospective observational study. BMJ. (2020) 369:m2094. doi: 10.1136/bmj.m2094

26. Verdoni L, Mazza A, Gervasoni A, Martelli L, Ruggeri M, Ciuffreda M, et al. An outbreak of severe Kawasaki-like disease at the Italian epicentre of the SARS-CoV-2 epidemic: an observational cohort study. Lancet. (2020) 395:1771-8. doi: 10.1016/S0140-6736(20)31103-X

27. World Health Organization. Scientific Brief: Multisystem Inflammatory Syndrome in Children and Adolescents With COVID-19. WHO Headquarters (HQ).

28. Nakamura A, Ikeda K, Hamaoka K. Aetiological significance of infectious stimuli in Kawasaki disease. Front Pediatr. (2019) 7:244. doi: 10.3389/fped.2019.00244

29. Hara T. [Kawasaki disease and innate immunity]. Nihon Rinsho. (2014) 72:1542-7.

30. Soy M, Keser G, Atagündüz P, Tabak F, Atagündüz I, Kayhan S. Cytokine storm in COVID-19: pathogenesis and overview of antiinflammatory agents used in treatment. Clin Rheumatol. (2020) 39:2085-94. doi: 10.1007/s10067-020-05190-5

31. Sun X, Wang T, Cai D, Hu Z, Chen J, Liao H, et al. Cytokine storm intervention in the early stages of COVID-19 pneumonia. Cytokine Growth Factor Rev. (2020) 53:38-42. doi: 10.1016/j.cytogfr.2020.04.002

32. Berger JR. COVID-19 and the nervous system. J Neurovirol. (2020) 26:143-8. doi: 10.1007/s13365-020-00840-5

33. Dugue R, Cay-Martínez KC, Thakur KT, Garcia JA, Chauhan LV, Williams $\mathrm{SH}$, et al. Neurologic manifestations in an infant with COVID-19. Neurology. (2020) 94:1100-2. doi: 10.1212/WNL.0000000000009653

34. Abdel-Mannan O, Eyre M, Löbel U, Bamford A, Eltze C, Hameed B, et al. Neurologic and radiographic findings associated with COVID-19 infection in children. JAMA Neurol. (2020) 77:1-6. doi: 10.1001/jamaneurol.20 20.2687

35. Götzinger F, Santiago-García B, Noguera-Julián A, LanaspaM, Lancella L, Calò Carducci FI, et al. COVID-19 in children and adolescents in Europe: a multinational, multicentre cohort study. Lancet Child Adolesc Health. (2020) 4:653-61. doi: 10.1016/S2352-4642(20) 30177-2

36. Kim L, Whitaker M, O'Halloran A, Kambhampati A, Chai SJ, Reingold A, COVID-NET Surveillance Team, et al. Hospitalization rates and characteristics of children aged $<18$ years hospitalized with laboratoryconfirmed COVID-19-COVID-NET, 14 states, March 1-July 25, 2020. MMWR Morb Mortal Wkly Rep. (2020) 69:1081-8. doi: 10.15585/mmwr. $\mathrm{mm} 6932 \mathrm{e} 3$

37. Han MS, Choi EH, Chang SH, Jin BL, Lee EJ, Kim BN, et al. Clinical characteristics and viral RNA detection in children with coronavirus disease 2019 in the Republic of Korea. JAMA Pediatr. (2020) 28:e203988. doi: 10.1001/jamapediatrics.2020.3988

Conflict of Interest: The authors declare that the research was conducted in the absence of any commercial or financial relationships that could be construed as a potential conflict of interest.

Copyright (C) 2021 Mazza, Di Giorgio, Martelli, Pelliccia, Pinotti, Quadri, Verdoni, Decio, Ruggeri and D'Antiga. This is an open-access article distributed under the terms of the Creative Commons Attribution License (CC BY). The use, distribution or reproduction in other forums is permitted, provided the original author(s) and the copyright owner(s) are credited and that the original publication in this journal is cited, in accordance with accepted academic practice. No use, distribution or reproduction is permitted which does not comply with these terms. 